\title{
REPRESENTASI KECANTIKAN DALAM MEDIA SOSIAL (ANALISIS SEMIOTIKA ROLAND BARTHES PADA VIDEO TUTORIAL MAKE-UP BEAUTY VLOGGER TASYA FARASYA DI YOUTUBE)
}

\author{
Ayu Nurdiana1), Nurma Yuwita ${ }^{2)}$ \\ 1), 2)Universitas Yudharta Pasuruan \\ 1)yuwita.nurma@gmail.com, 2)nurma@yudharta.ac.id
}

\begin{abstract}
Abstrak: Persoalan yang dikaji dalam skripsi ini, yaitu: (1) bagaimana representasi kecantikan pada video tutorial make-up Beauty Vlogger Tasya Farasya di Youtube dengan analisis semiotika Roland Barthes? Untuk mengungkap masalah tersebut secara menyeluruh dan mendalam, penelitian ini menggunakan metode kualitatif deskriptif dengan analisis semiotika Roland Barthes. Peneliti menggunakan jenis penelitian deskriptif karena peneliti menafsirkan representasi kecantikan pada video tutorial tersebut. Dari hasil penelitian ini ditemukan bahwa kecantikan adalah (1) ketika memakai foundation, (2)memakai concealer dibagian bawah mata, (3) memakai blush on pada pipi,(4) memakai bedak, (5)memakai highlight\&contour pada bagian wajah,(6) memakai eye shadow dibagian mata, (7)memakai eye liner dibagial kelopak mata, (8)mengukir pensil alis dengan cantik, (9)memakai maskara pada bulumata, (10)mengoles lipstick pada bibir.

Berdasarkan hasil penelitian ini beberapa saran yang dapat dijadikan bahan pertimbangan antara lain: (1) Bagi masyarakat, Supaya lebih bijak dan lebih cermat berpikir bahwa terkadang tidak semua kata "cantik" itu harus memakai dengan makeup. (2) Bagi akademis, dapat menambah pengetahuan tentang makna-makna yang berkenaan video konten kecantikan di youtube, agar lebih mudah memaknai makna cantik yang sesungguhnya.
\end{abstract}

Kata Kunci: Representasi Kecantikan,Media, Sosial,Denotatif, Semiotika

\begin{abstract}
The issues that are studied in this thesis are: (1) how is the representation of beauty in the make-up tutorial video of Beauty Vlogger Tasya Farasya on Youtube with semiotic analysis of Roland Barthes?

To reveal this problem thoroughly and deeply, this study uses a descriptive qualitative method with Roland Barthes' semiotic analysis. Researchers use this type of descriptive research because the researcher interprets the representation of beauty in the video tutorial. From the results of this study it was found that beauty is (1) when using foundation, (2) wearing concealer under the eyes, (3) wearing blush on the cheeks, (4) using powder, (5) using highlight \& contour on the face, (6) ) wear eye shadow on the eye, (7) wear eye liner on the part of the eyelid, (8) carve eyebrow pencil beautifully, (9) apply mascara to the lashes, (10) rub lipstick on the lips.

Based on the results of this study, several suggestions that can be taken into consideration include: (1) For the community, in order to be wiser and more careful in thinking that sometimes not all the words "beautiful" must be used with make-up. (2) For academics, it can increase knowledge about the meanings regarding beauty content videos on YouTube, so that it is easier to interpret the true meaning of beauty
\end{abstract}

Keywords: Beauty Representation, Social Media, Denotative, Semiotics 


\section{PENDAHULUAN}

Teknologi yang semakin canggih, membuat para masyarakat mudah untuk melakukan berbagai akses yang diinginkan. Karena adanya teknologi yang baru, membantu masyarakat dalam bidang pekerjaan maupun ekonomi. Dan juga memudahkan para pengguna teknologi untuk saling berkomunikasi atau memberi informasi meskipun terhalang oleh jarak dan waktu.

Kemajuan teknologi media komunikasi dengan berbagai jenis terus meningkat. "Media sosial menjadi aplikasi yang dirancang guna mempermudah interaksi dan komunikasi dalam dunia maya melalui jaringan internet, namun karena adanya pandemi virus COVID-19 menyebabkan perubahan fungsi dari media sosial tersebut". ${ }^{1}$ Ini membawa pengaruh yang besar bagi masyarakat dunia. Banyak faktor yang mengajak manusia untuk hidup serba instan, mewah, dan budaya barat yang telah masuk ke masyarakat Indonesia dari berbagai sisi. Perihal ini menjadikan terdapatnya perpindahan tata nilai moral serta budaya yang terjalin. Bermacam- macam media komunikasi baik visual serta audiovisual juga muncul di warga, perihal ini jadi kebutuhan mendasar untuk tiap manusia. Apalagi inovasi yang terus menerus muncul dalam media komunikasi menjadi lebih canggih dari sebelumnya.

Namun dari banyaknya konten youtube, peneliti mengambil salah satu seorang konten youtube yang bernama Tasya Farasya. Dalam konten youtubenya, dia melakukan berbagai kegiatan seperti, menggunakan make-up, tips-tips kesehatan atau produk make-up dan masih banyak lagi. Dari beragam video telah di upload di konten youtubenya, peneliti mengambil salah satu video tutorial make-up untuk dijadikan bahan penelitian pada akhir tugas kuliah. Hingga saat ini, jumlah subscriber di konten youtube Tasya Farasya sudah mencapai 3,57 juta orang. Berdasarkan banyaknya video yang diposting, tak sedikit yang menyukai dan memberikan komentar positif dari orang-orang yang melihat videonya. Tampil cantik adalah idaman semua wanita, namun terkadang seseorang malas memakai make-up berlebih untuk sehari-hari. Banyak tips dan trik dari Tasya Farasya untuk daily make up yang tampak alami dan juga tips-tips lain soal kecantikan. Sehingga tak heran apabila jumlah subscribenya melebihi 3,57 juta orang, karena dia memang sangat detail untuk memberikan informasi

1 Sholihun, Gatut Setiadi, and Nurma Yuwita. "EVOLUSI PENGGUNAAN MEDIA SOSIAL DI SMP BHINNEKA TUNGGAL IKA PASURUAN SEBAGAI SARANA ALTERNATIF PEMBELAJARAN DI RUMAH". Al-Ittishol: Jurnal Komunikasi dan Penyiaran Islam 1, no. 2 (June 29, 2020): 116-130. Accessed November 13, 2021. https://ejournal.iaiskjmalang.ac.id/index.php/ittishol/article/view/176. 


\section{คL-ITTISHDL \\ Jurnal Komunikasi dan Penyiaran Islam}

Institut Agama Islam Sunan Kalijogo Malang

P-ISSN: 2721-964X / E-ISSN: 2721-9631 Volume 3 Nomor 1 Januari 2022

kepada penonton atau penggemarnya mengenai berbagai produk kosmetik atau kecantikan. Selain itu juga, Make-up yang di aplikasikan pada wajah terus mengalami perubahan dan perkembangan dari masa ke masa. Karena setiap tahun selalu ada perubahan atau gaya saat menggunakan kosmetik dan banyak bermunculan kosmetik-kosmetik untuk mempercantik diri.

Jadi pada konsep Roland Barthes, ciri konotatif tidak hanya mempunyai arti bonus tetapi pula memiliki kedua bagian ciri denotatif yang melandasi keberadannya. Sebetulnya inilah sumbangan Barthes yang sangat berarti buat penyempurnaa semiologi Saussure, yang menyudahi pada penandaan dalam tataran denotatif. Banyaknya tutorial make-up yang ada di media sosial, mengkontruksikan wanita cantik pada penampilan fisik, sehingga menimbulkan persepsi tentang kata cantik yang membuat para wanita tidak percaya diri. Video Make-up Tutorial Beauty Vlogger Tasya Farasya di Youtube yang berlandaskan pada sebuah survey ini menjadi sesuatu yang menarik untuk diteliti. Karena penulis melihat sisi yang unik pada penyajiannya, bahwa wanita akan terlihat memancarkan kecantikan secara fisik seperti sosok model jika memakai make-up.

Dengan adanya komen, viewers, dan like disetiap videonya merupakan suatu dukungan untuk melakukan penelitian pada video tersebut. Maka dari itu, penulis ingin meneliti seperti apa representasi kecantikan dalam video tersebut dengan analisis semiotika Roland Barthes meliputi dua kategori yaitu denotatif dan konotatif.

\section{METODE}

Dalam penelitian, peneliti menganalisa semiotika dan ditekankan pada representasi tutorial make-up Tasya Farasya di Youtube dengan menggunakan metode penelitian kualitatif deskriptif. Moleong (2014: 6) mengatakan bahwa, penelitian kualitatif merupakan penelitian yang bermaksud untuk memahami fenomena-fenomena apa yang dialami oleh subjek penelitian., misalnya meliputi perilaku, motivasi, tindakan, persepsi dengan cara mendeskripsikan ke dalam sebuah bentuk kata-kata dan bahasa pada suatu konteks khusus yang alamiah dan memanfaatkan berbagai macam metode alamiah lainnya.

Data dari video tersebut akan dikaji melalui kajian semiotika dengan mengaitkan tanda-tanda yang muncul dalam tayangan tersebut di aplikasikan kedalam peta tanda Roland Barthes. Dalam peta tanda tersebut akan diuraikan unsur-unsur pembangunan sebuah makna 
sesuai dengan kerangka pikiran yang sudah peneliti buat melalui makna konotatif dan makna denotatif sebagaimana representasi yang akan diteliti.

Peneliti menggunakan pendekatan kualitatif deskriptif untuk menganalisis video tutorial make-up Tasya Farasya di youtube. Penelitian kualitatif adalah penelitian yang menggunakan latar ilmiah, dengan maksud menafsirkan fenomena yang terjadi dan dilakukan dengan melibatkan berbagai metode yang ada. Penelitian ini, fokus pada tayangan video tutorial make-up di youtube oleh Tasya Farasya. Yang kemudian penelitian ini ditekankan pada analisis representasi seorang youtuber yang mengkontruksikan bahwa dengan memakai make-up salah satu definisi cantik.

\section{HASIL DAN PEMBAHASAN}

\section{Menciptakan kepercayaan bahwa wanita akan terlihat cantik jika memakai foundation pada video tutorial make-up Tasya Farasya}

Tasya memberikan kepercayaan terhadap setiap wanita bahwa dengan memakai foundation pada bagian wajah akan terlihat mulus, karena foundation mampu menutupi bagian wajah yang kurang sempurna. Seperti jerawat atau bekas luka lainnya. Namun kebanyakan wanita menggunakan foundation yang hight atau lebih terang agar terlihat mempunyai kulit yang putih.

2. Menciptakan kepercayaan bahwa wanita akan terlihat cantik menggunakan concealer

Penggunaan concealer pada make-up memang sudah wajar, karena alat make-up ini menambahkan kesan cantik dan indah merata di area mata. Kebanyakan wanita menggunakan concealer ini, untuk menutupi bagian bawah mata yang terlihat kusam atau hitam. Maka dari itu, agar menyamarkan itu semua Tasya memberikan concealer agar semakin cantik.

\section{Memberikan kepercayaan bahwa wanitaakan terlihat cantik saat memakai blush on} Menggunakan blush on berwarna orange meskipun kebanyakan memakai warna pink. Tapi itu tidak membuat Tasya kurang percaya diri, melainkan dengan menggunakan blush on yang berwarna orange juga menambah kesan cantik dan tampil cantik saat ingin pergi ke kantor.

\section{Memberikan kepercayaan bahwa wanita terlihat cantik saat memakai bedak}


Menunjukkan bahwa wanita memang tak lepas dari yang namanya bedak. Karena bedak merupakan alat utama saat menggunakan make-up. Terkadang wanita juga hanya mennggunakan bedak untuk menmbah kesan cantik pada wajahnya, meskipun dengan tidak menmbah kosmetik lainnya.

5. Memberikan kepercayaan bahwa wanita terlihat cantik saat memakai highlighter\&contour

Terlihat bahwa rahang tirus dan wajah mengkilap adalah idaman setiap wanita. Maka dari itu, dalam pemakaian make-up ada penambahan highlighter dan contour gunanya untuk menambah kesan berkilau pada bagian wajahnya dan terlihat tirus.

\section{Memberikan kepercayaan bahwa wanita terlihat cantik saat memakai eye shadow}

Terlihat bahwa Tasya memberikan kesan cantik pada bagian kelopak mata, karena menggunakan eye shadow yang cocok untuk pergi bekerja ke kantor. Selain itu juga, Tasya juga menambah warna yang agak gelap supaya mata terlihat segar dan semakin cantik.

\section{Memberikan kepercayaan bahwa wanita terlihat cantik saat memakai eye liner}

Tasya memberikan eye liner dan membentuknya dengan swing atau terdapat ujung lancip untuk menambah kesan agar terlihat semakin cantik. Dan selain itu juga, Tasya juga mengkontruksikan kepada setiap wanita, bahwa saat memakai make-up harus menambahkan eye liner pada mata. Karena itu suatu tambahan agar make-up yang dia gunakan mempunyai hasil yang memuaskan.

\section{Memberikan kepercayaan bahwa wanita terlihat cantik saat memakai pensil alis}

Wanita memang cantik jika mempunyai alis yang hitam dan tegak. Sambil meragukan hasil akhir dari pensil alis yang dia buat, ternyata dia berubah menjadi senang karena dia bisa membentuk alis yang lurus dan tegak sesuai dengan yang dia inginkan. Banyak wanita yang menginginkan alis berwarna hitam,lurus sesuai garis alis, dan terlihat cantik. Namun sayangnya, terkadang setiap orang mempunyai bentuk alis yang berbeda-beda. Maka dari itu, Tasya menunjukkan bahwa alis akan terlihat bagus dengan menggunakan pensil alis dari produk tersebut.

9. Memberikan kepercayaan bahwa wanita terlihat cantik saat memakai mascara Memakai maskara akan membuat bulumata terlihat lentik. Tasya juga membuktikan bahwa maskara yang dia pakai pada video tersebut memanglah bagus.

10. Memberikan kepercayaan bahwa wanita akan terlihat cantik saat memakai lipstick 
Tasya memberikan kepercayaan kepada setiap penonton bahwa memakai lipstik berwarna kecoklatan cocok untuk pergi ke kantor. Selain itu juga, Tasya juga memberikan tips agar tidak memakai warna yang terlalu mencolok saat pergi ke tempat formal seperti saat bekerja. Menggunakan make-up merupakan salah satu yang sudah biasa bagi para wanita. Mulai dari memakai alas bedak sampai akhirnya memakai lisptik untuk memperindah bibir. Penambahan kesan cantik dan mempesona dalam setiap tampilan juga dambaan setiap orang.

\section{KESIMPULAN}

Berdasarkan penelitian yang dilakukan, maka dapat peneliti simpulkan bahwa analisis semiotika Roland Barthes yang dilakukan pada Representasi kecantikan dalam media sosial (video make-up tutorial beauty vlogger Tasya Farasya di youtube) yaitu, bahwa wanita akan terlihat cantik jika memakai foundation, concealer, blush on, bedak, highlight\&contour,eye shadow, eye liner, pensil alis, maskara, sampai lipstick.

Dari tanda-tanda denotatif tersebut menjelaskan bahwa :

a. Wajah yang cantik dan mulus saat menggunakan foundation

b. Bagian bawah mata akan terlihat sempurna dan cantik dengan menggunakan concealer

c. Memakai blush on menampakkan wajah yang merona dan terlihat semakin muda

d. Pemakaian bedak membuat wajah terlihat cantik, karena membuat wajah terlindungi dan membantu mengatasi masalah pada wajah

e. Waajah akan terlihat mengkilap (glowing) saat menggunakan highlighter pada makeup, Dan juga terlihat tirus saat menggunakan contour pada bagian rahang pipi.

f. Mata yang indah yakni saat diberikan polesan dengan eye shadow

g. Cantik saat menggunakan eye liner menggambarkan pesona pada bagian mata

h. Mempunyai alis berwaran hitam dan berbentuk tegak sesuai dengan garisnya, menunjukkan kecntikan

i. Bulumata yang terlihat lentik dan cantik saat menggunakan maskara

j. Bibir yang indah dan cantik saat dipoles dengan warna lipstick

Dan dari tanda-tanda konotatif tersebut menjelaskna bahwa :

a. Kulit wajah yang cantik identik dengan wajah putih dan mulus

b. Dengan memakai concealer bagian bawah mata akan terlihat cantik

c. Penggunaan blush on menampakkan wajah terlihat mudah karena warna pipi yang merona

d. Perempuan akan semakin cantik bila memakai bedak 
e. Highlighter\&contour membuat tampilan wajah mengkilap dan terlihat tirus bagian wajah

f. Kelopak mata akan terlihat cantik ketika ditambahkan eye shadow

g. Terlihat indah pada bagian mata merupakan idaman setiap wanita dengan memakai eye liner

h. Alis yang sempuran merupakan alis yang berwarna hitam dan tegak lurus sesuai dengan garis alis

i. Keinginan wanita yang mempunyai bulumata yang lentik

j. Bentuk bibir yang sempurna akan terlihat cantik saat memakai lipstick

\section{SARAN}

Dari kesimpulan yang telah dipaparkan diatas, peneliti mendapat inti penting untuk dijadikan saran, diantaranya :

\section{Bagi Masyarakat}

Dari video Tasya Farasya tersebut, dapat kita lihat bahwa paras atau make-up merupakan suatu identika kecantikan. Perkembangan tata rias atau make-up yang diperagakan oleh Tasya Farasya mampu menjadi contoh para Make-Up Artist (MUA) untuk menambah sklill meriasnya. Supaya bisa menambah mengenal produk yang mudah dijangkau namun mempunyai hasil yang sempurna untuk para pemula atau yang sudah ahli dalam ber Make-up. Selain itu juga, untuk para Beauty Vlogger lainnya atau para youtuber supaya memperkembangkan video vlog mengenai tutorial Make-up.

\section{Bagi Akademi}

Untuk peneliti selanjutnya, peneliti berharap dapat menambah pengetahuan tentang makna-makna yang berkenaan video konten kecantikan di youtube, agar lebih mudah memaknai makna cantik yang sesungguhnya. Selain itu juga, agar lebih memahami tantang semiotika, makna denotatif dan konotatif sesuai dengan peta konsep Roland Barthes. 


\section{DAFTAR PUSTAKA}

Fiske,John.2010. Budaya dan Studi Komunikasi. Yogyakarta: Jala Sutra

Kriyanto, 2012. Riset Komunikasi. Kencana

Moleong, Lexy J. 2018. Metode Penelitian Kualitatif. Edisi Revisi. Bandung: PT. Remaja Rosdakarya

Nasrullah,2016,Media Sosial Perspektif Komunikasi, Budaya, Sosioteknologi, Cet.Kedua Simbiosa Rakatama Media, Bandung

Nawiroh Vera, Semiotika Dalam Riset Komuniaksi. Bogor: Ghali Indonesia, 2014

Ritzer, George. 2012. Teori Sosiologi. Yogyakarta: Pustaka Pelajar. Sangadji,2010. Metodologi Penelitian. Andi

Sobur, Alex. 2018. Semiotika Komunikasi, Bandung: Remaja Rosdakarya.

Sholihun, Gatut Setiadi, and Nurma Yuwita. "EVOLUSI PENGGUNAAN MEDIA SOSIAL DI SMP BHINNEKA TUNGGAL IKA PASURUAN SEBAGAI SARANA ALTERNATIF PEMBELAJARAN DI RUMAH ". Al-Ittishol: Jurnal Komunikasi dan Penyiaran Islam 1, no. 2 (June 29, 2020): 116-130. https://ejournal.iaiskjmalang.ac.id/index.php/ittishol/article/view/176.

Sugiyono,2012. Metode Penelitian Kuantitatif, Kualitatif, dan R\&D. Bandung: Penerbit Alfabeta Jurnal :

Firdaus, 2018. Makna kecantikan dalam iklan (Analisis Semiotika Roland Barthes Iklan Citra Sakura Fair UV Versi Febby Rastanty)

Arisanti, 2019 Analisis Makna Cantik Dalam Video Youtube Tasya Farasya "7 Hari No Makeup Challenge!" (Analisis Semiotika Charles Canders Pierce)

Internet dan Artikel :

Korichi, R., Pelle-De-Queral, D., Gazano, G., \& Aubert, A. (2010). Why women use makeup: Implication of psychological traits in makeup functions. J.Cosmet.Sci. 59, 127-137.

https://www.slideshare.net/jazulie212/makna-konotatif-dan-denotatif

http://www.youtube.com.diakses05mei2020

https://www.idntimes.com/hype/entertainment/nur-malika-1/beauty-youtuberterpopuler-tajir-melintir-1/2 